\title{
Nutritional Status and Physical Activity Pattern as Risk Factors for Non-Communicable Diseases among Occupational Bus Drivers
}

\author{
Rashmi R ${ }^{1}$, Vidyavati H G ${ }^{2}$, C N Manjunath ${ }^{3}$ \\ ${ }^{1}$ Dietitian, CDE, Department of Nutrition, Sri Jayadeva Institute of Cardiovascular Sciences and Research, \\ Bangalore. \\ ${ }^{2}$ Senior Dietitian, RD, Department of Nutrition, Sri Jayadeva Institute of Cardiovascular Sciences and Research, \\ Bangalore. \\ ${ }^{3}$ Director, Sri Jayadeva Institute of Cardiovascular Sciences and Research, Bangalore.
}

Corresponding Author: Rashmi R

\begin{abstract}
It is anticipated that occupational bus drivers are at risk of non-communicable diseases. Present study aims at assessing the nutritional status and analyzing the risk factors associated, which could increase the probability of non-communicable diseases among bus drivers and conductors working for Karnataka State Road Transport Corporation.120 professional drivers and conductors who attended annual health checkup were included. A pre designed questionnaire elicited information about anthropometry, dietary, physical activity and sleep pattern of the subjects. Lipid profile and blood glucose levels were recorded from annual health check up reports. Mean age of the subjects was 44 years with BMI ranging between $25-29.9 \mathrm{Kg} / \mathrm{m} 2.73 .3 \%$ had mixed diet pattern, $40 \%$ skip their meals sometime and majority eat their meals outside home most of the days in a week.74.2\% didn't indulge in physical activity. $56.7 \%$ subjects slept six to seven hours per day. $17.5 \%$ were diabetic, $52.5 \%$, 80.8\% and 17.5\%had higher serum triglycerides, Low Density Lipoprotein and total cholesterol respectively. 57.5\% had lower High Density Lipoprotein levels. 8.3\%, 21.7\% and 15\% were smokers, alcoholic and tobacco chewers respectively. ' $t$ ' test analysis showed significant difference between energy, protein and visible fat intake with that of Recommended Dietary Allowance and Estimated Average Requirement. Total cholesterol, Low Density Lipoprotein and serum triglycerides had positive correlation with energy, protein and visible fat intake and BMI. Considerable risk factors for non-communicable diseases were observed among the subjects; effective diet counseling with regular follow up and monitoring is necessary to prevent the same.
\end{abstract}

Key Words: Occupational drivers, nutritional status, risk factors, dietary pattern, physical activity, Non Communicable Diseases, effective counseling.

\section{INTRODUCTION}

Balanced diet plays a key role in attaining a healthy life; it refers to having right nutrients in right proportions to achieve proper bodily function. Also regular physical activity with good sleep pattern aids an individual to lead a healthy life and Non-Communicable diseases like diabetes mellitus, hypertension, cardiovascular diseases, etc. can be prevented.
Workers of transport department especially drivers and conductors showed to have improper lifestyle in terms of diet, physical activity, sleep pattern, habits, etc. The preeminent reason could be lack of education and time accompanied by shift timings. Bus or truck drivers are at higher risk of various chronic diseases especially cardiovascular diseases [1]. They can easily get into unfavorable risk factors such as obesity, 
poor dietary habits, sedentary lifestyle, etc which accompanied with job stress leads to hypertension, dyslipidemia and diabetes in turn resulting in higher probability of cardiovascular events [2, 3]. Common risk factors of drivers and conductors include prolonged sitting/ standing, decreased rest, disturbed sleep pattern, irregular food habits, stress and pressure for safety of the passengers [4].

Professional drivers munch on unhealthy, handy snacks and choose for more salt and saturated fat, with fewer intakes of fruits and vegetables [5-7]. Intake of junk foods may increase their risk for non-communicable diseases mainly CVD. Also it is quite common that drivers and conductors have to work in both day and night shifts, which apparently affect their diet, physical activity and sleep pattern. There was a significant difference in night shift workers when compared with day shift ones with respect to prevalence of being overweight increased meat consumption and lower fruits and vegetable intake[8].

One of the previous studies reveals that the night shift workers derived higher energy from saturated fats and had lesser vegetables and fruits compared to day workers [9]. Also it was found that night workers had poor snacking choices with possible reasons could be time constraints and lack of education.

This study aims at understanding and assessing the impact of lifestyle modifications on the nutritional status of employees working in Karnataka State Road Transport Corporation. Primary objective was to conduct the anthropometric assessment, investigate the dietary, physical activity and sleep pattern and correlate it with lipid profile of the subjects. Data was collected using standard tools, appropriate statistical tests were applied and inferences were drawn.

Also subjects were given simple advice on choosing healthy food, regular physical activity, stress management, practicing good lifestyle, etc. Emphasizing on these parameters could prevent the subjects from various Non-Communicable Diseases.

\section{MATERIALS AND METHODS/ METHODOLOGY}

Sample selection: The study was conducted in a Tertiary care hospital (Sri Jayadeva Institute of Cardiovascular Sciences and Research) in Bangalore. The study population included 120 male bus drivers and conductors employed by Karnataka State Road Transport Corporation (KSRTC) selected using simple random sampling technique, who had visited the hospital for annual health checkup between January 2020 to May 2020. Only male subjects were included as females were less in number. Among 120 subjects selected in the study 55 were driver cum conductors, 48 were drivers and 17 were conductors.

Study design: It was a cross-sectional study conducted using a pre-requisite questionnaire to elicit information on basic data, anthropometry, biochemical parameters, diet, physical activity and sleep pattern of the subjects.

Data collection: Data was collected using personal interview technique; it included basic information like age, education qualification, occupation, monthly income, family type, family size, habit of smoking, tobacco chewing or alcoholism, etc. Anthropometric measurements for weight and height were collected using calibrated weighing machine and height scale. BMI was calculated. Obtained values were compared with Asian BMI standards and subjects whose BMI was between 18.5-22.9 were categorized as normal, 23-24.9 as overweight, 25-29.9 as pre obese and those $>30$ as obese.

Blood samples collected during medical camp to test for Fasting Blood Sugar, Post Prandial Blood Sugar and lipid profile using GOD-POD method for blood sugar, CHOD-PAP, direct method and GPO-PAP for lipid profile were recorded. These values were compared with reference 
Rashmi $R$ et.al. Nutritional status and physical activity pattern as risk factors for non-communicable diseases among occupational bus drivers.

range given by Centre for Disease Control (CDC), May 2019.

Eliciting information on dietary pattern of the subject was done by collecting data regarding food pattern (Vegetarian or Non vegetarian), number of meals taken per day, habit of skipping meals, oil used for cooking medium, quantity of oil used per month, etc. 24hrs dietary recall method was used, through this average intake of energy, protein and visible fat was calculated and compared with Estimated Average requirement (EAR) 2020 and Recommended Dietary Allowance (RDA) 2010. Food Frequency Questionnaire including 30 items was framed and frequency of consumption of those foods was assessed.

Physical activity level of the subjects was assessed based on the time spent on various activities such as walking, jogging, yoga, exercise etc. Sleep pattern was evaluated by collecting data on sleep and wake up time.

Statistical analysis and Interpretation: The collected data was coded and entered using MS excel 2007 and analyzed using SPSS software. Basic statistical methods like percentage were used to analyze the basic data, anthropometry, food habit, physical activity and sleep pattern, etc. Mean and standard deviation were used to analyze the intake and adequacy of nutrients. Student ' $t$ ' test was performed to assess for association between mean intake and EAR and RDA of the nutrients. Pearson Chi square test was performed to check the association of BMI with age group. Spearman Correlation test was used to evaluate the correlation between nutrient intake, BMI and sleep pattern of the subjects with glucose and lipid profile. All statistical tests were performed at 0.05 level of significance and confidence interval of $95 \%$.

\section{RESULT}

TABLE - 1. Classification of Respondents by Personal characteristics, $\mathrm{N}=120$

\begin{tabular}{|l|l|l|l|}
\hline Characteristics & Category & \multicolumn{2}{|l|}{ Respondents } \\
\cline { 2 - 4 } & & Number & Percent \\
\hline \multirow{3}{*}{$\begin{array}{l}\text { Age group } \\
\text { (years) }\end{array}$} & $30-39$ & 24 & 20.0 \\
\cline { 2 - 4 } & $40-49$ & 54 & 45.0 \\
\cline { 2 - 4 } & $50-59$ & 42 & 35.0 \\
\hline Educational level & SSLC & 52 & 43.3 \\
\cline { 2 - 4 } & PUC & 47 & 39.2 \\
\cline { 2 - 4 } & Graduation & 21 & 17.5 \\
\hline Occupation & Driver & 43 & 35.8 \\
\cline { 2 - 4 } & Conductor & 11 & 9.2 \\
\cline { 2 - 4 } & $\begin{array}{l}\text { Driver } \\
\text { conductor }\end{array}$ & 50 & 41.7 \\
\cline { 2 - 4 } & Mechanic & 16 & 13.3 \\
\hline Total & & 120 & 100.0 \\
\hline
\end{tabular}

Table 1 depicts the age group, educational level and occupation of the respondents.

TABLE - 2. Classification of Respondents by Food habit, $\mathbf{N}=\mathbf{1 2 0}$

\begin{tabular}{|l|l|l|l|}
\hline \multirow{2}{*}{ Characteristics } & \multirow{2}{*}{ Category } & \multicolumn{2}{|l|}{ Respondents } \\
\cline { 2 - 4 } & & Number & Percent \\
\hline \multirow{5}{*}{ Food habit } & Vegetarian & 24 & 20.0 \\
\cline { 2 - 4 } & Mixed diet & 88 & 73.3 \\
\cline { 2 - 4 } & $\begin{array}{l}\text { Ovo } \\
\text { vegetarian }\end{array}$ & 8 & 6.7 \\
\hline \multirow{2}{*}{$\begin{array}{l}\text { Frequency usage of non- } \\
\text { vegetarian }\end{array}$} & Weekly & 45 & 37.5 \\
\cline { 2 - 4 } & Fortnightly & 31 & 25.8 \\
\cline { 2 - 4 } & Monthly & 12 & 10.0 \\
\cline { 2 - 4 } & No & 32 & 26.7 \\
\hline Total & & 120 & 100.0 \\
\hline
\end{tabular}

Table 2 gives the food habit and frequency of non-veg consumption of the subjects,

TABLE - 3. Response on Meal pattern and Skipping of meals, $\mathrm{N}=120$

\begin{tabular}{|l|l|l|l|}
\hline \multirow{2}{*}{ Characteristics } & \multirow{2}{*}{ Category } & \multicolumn{2}{|l|}{ Respondents } \\
\cline { 3 - 4 } & & Number & Percent \\
\hline \multirow{2}{*}{$\begin{array}{l}\text { Number of meals consumed } \\
\text { Skipping of meals }\end{array}$} & Two & 25 & 20.8 \\
\cline { 2 - 4 } & Three & 95 & 79.2 \\
\hline \multirow{5}{*}{ Type of meal skipped } & Yes & 24 & 20.0 \\
\cline { 2 - 4 } & No & 48 & 40.0 \\
\cline { 2 - 4 } & Sometimes & 48 & 40.0 \\
\hline \multirow{3}{*}{ Type of oil used } & Breakfast & 22 & 18.3 \\
\cline { 2 - 4 } & Lunch & 47 & 39.2 \\
\cline { 2 - 4 } & Dinner & 3 & 2.5 \\
\hline Total & Sunflower & 88 & 73.3 \\
\cline { 2 - 4 } & Groundnut & 24 & 20.0 \\
\cline { 2 - 4 } & Others & 8 & 6.7 \\
\hline & & 120 & 100.0 \\
\hline
\end{tabular}

Table 3 depicts the meal pattern of the respondents, it includes number of meals consumed per day, skipping of meals, if yes which meal is skipped and also the type of oil used for cooking at home. 


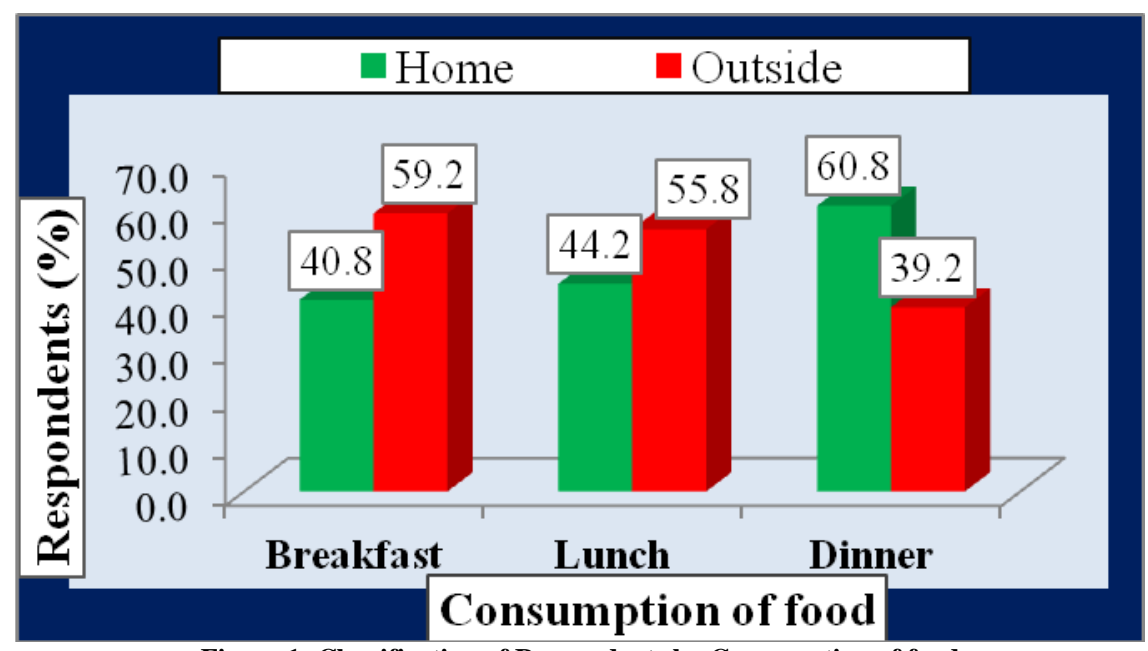

Figure 1: Classification of Respondents by Consumption of food

Fig 1 depicts the consumption of food outside home by the respondents.

TABLE - 4. Classification of Respondents by Anthropometric measurements, $N=120$

\begin{tabular}{|l|l|l|l|}
\hline Characteristics & Category & \multicolumn{2}{|l|}{ Respondents } \\
\cline { 2 - 4 } & & Number & Percent \\
\hline \multirow{4}{*}{ Height (cm) } & $155-165$ & 42 & 35.0 \\
\cline { 2 - 4 } & $166-170$ & 44 & 36.7 \\
\cline { 2 - 4 } & $171-180$ & 34 & 28.3 \\
\hline \multirow{3}{*}{ Weight (kg) } & $51-70$ & 38 & 31.7 \\
\cline { 2 - 4 } & $71-80$ & 51 & 42.5 \\
\cline { 2 - 4 } & $81+$ & 31 & 25.8 \\
\hline Total & & 120 & 100.0 \\
\hline
\end{tabular}

Table 4 depicts the anthropometric measurements; it includes average height and weight of the respondents.

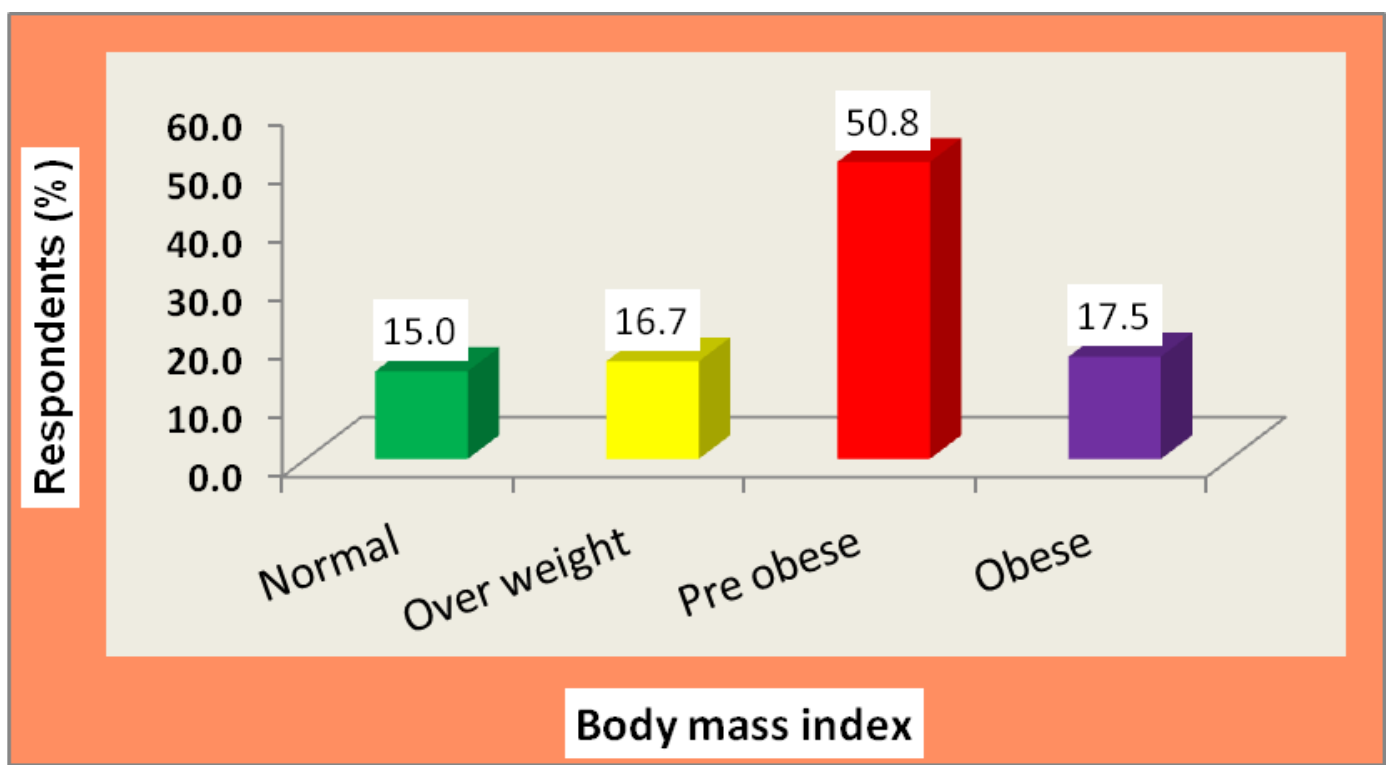

Figure 2 Classification of Respondents by Body mass index

Fig 2 states the BMI of the TABLE - 5. Response on Body mass index by Age group, respondents in comparison with Asian BMI Standards.

\begin{tabular}{|c|c|c|c|c|c|c|c|}
\hline \multirow{3}{*}{$\begin{array}{l}\text { Body mass } \\
\text { index }\end{array}$} & \multicolumn{6}{|c|}{ Respondents by Age (years) } & \multirow{3}{*}{$\begin{array}{l}\chi^{2} \\
\text { Test }\end{array}$} \\
\hline & \multicolumn{2}{|c|}{$30-39$} & \multicolumn{2}{|c|}{$40-49$} & \multicolumn{2}{|c|}{$50-59$} & \\
\hline & $\mathbf{N}$ & $\%$ & $\mathbf{N}$ & $\%$ & $\mathbf{N}$ & $\%$ & \\
\hline Normal & 5 & 20.8 & 8 & 14.8 & 5 & 11.9 & \multirow{4}{*}{$\begin{array}{l}2.50 \\
\text { NS }\end{array}$} \\
\hline Over weight & 2 & 8.3 & 11 & 20.4 & 7 & 16.7 & \\
\hline Pre obese & 13 & 54.2 & 26 & 48.1 & 22 & 52.4 & \\
\hline Obese & 4 & 16.7 & 9 & 16.7 & 8 & 19.0 & \\
\hline Total & 24 & 100.0 & 54 & 100.0 & 42 & 100.0 & \\
\hline
\end{tabular}


Rashmi $R$ et.al. Nutritional status and physical activity pattern as risk factors for non-communicable diseases among occupational bus drivers.

Table 5 depicts the response of Body Mass Index (BMI) by age group, Chi Square test shows no significant difference in BMI among the respondents of different age group at $5 \%$ level of significance.

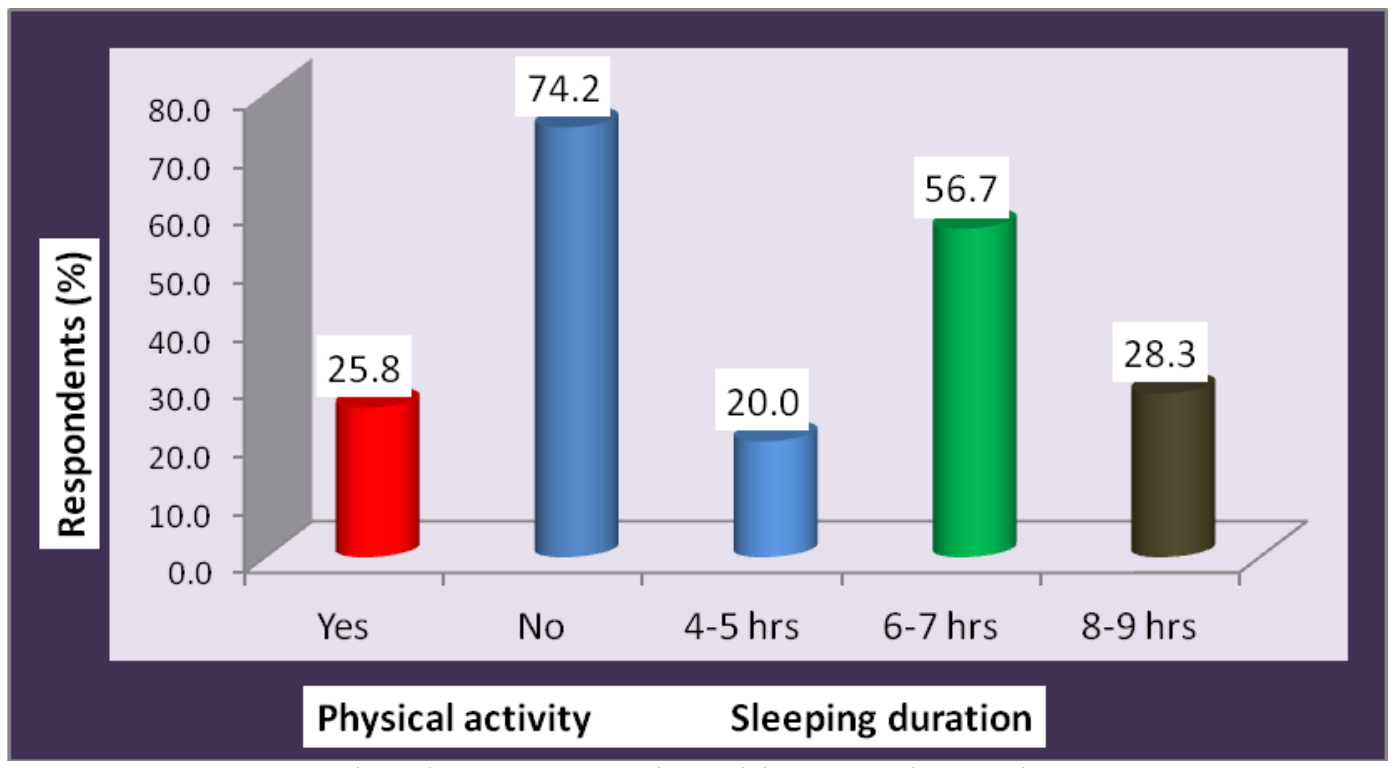

Figure 3 Response on Physical activity and sleeping duration

Fig 3 depicts the Physical activity level and sleep duration of the subjects.

TABLE - 6. Response on Co morbidity and Personal habits, N=120
\begin{tabular}{|l|l|l|l|}
\hline Aspects @ & Category & Respondents \\
\cline { 3 - 4 } & & Number & Percent \\
\hline \multirow{4}{*}{ Comorbidity @ } & None & 64 & 53.3 \\
\cline { 2 - 4 } & HTN & 7 & 5.8 \\
\cline { 2 - 4 } & Diabetics & 21 & 17.5 \\
\cline { 2 - 4 } & Others & 22 & 18.3 \\
\hline \multirow{4}{*}{ Personal habit @ } & None & 74 & 61.7 \\
\cline { 2 - 4 } & Smoking & 10 & 8.3 \\
\cline { 2 - 4 } & Alcohol & 26 & 21.7 \\
\cline { 2 - 4 } & Tobacco & 18 & 15.0 \\
\hline & & 120 & 100.0 \\
\hline
\end{tabular}

Table 6 shows the co morbidity status and personal habits of the subjects.

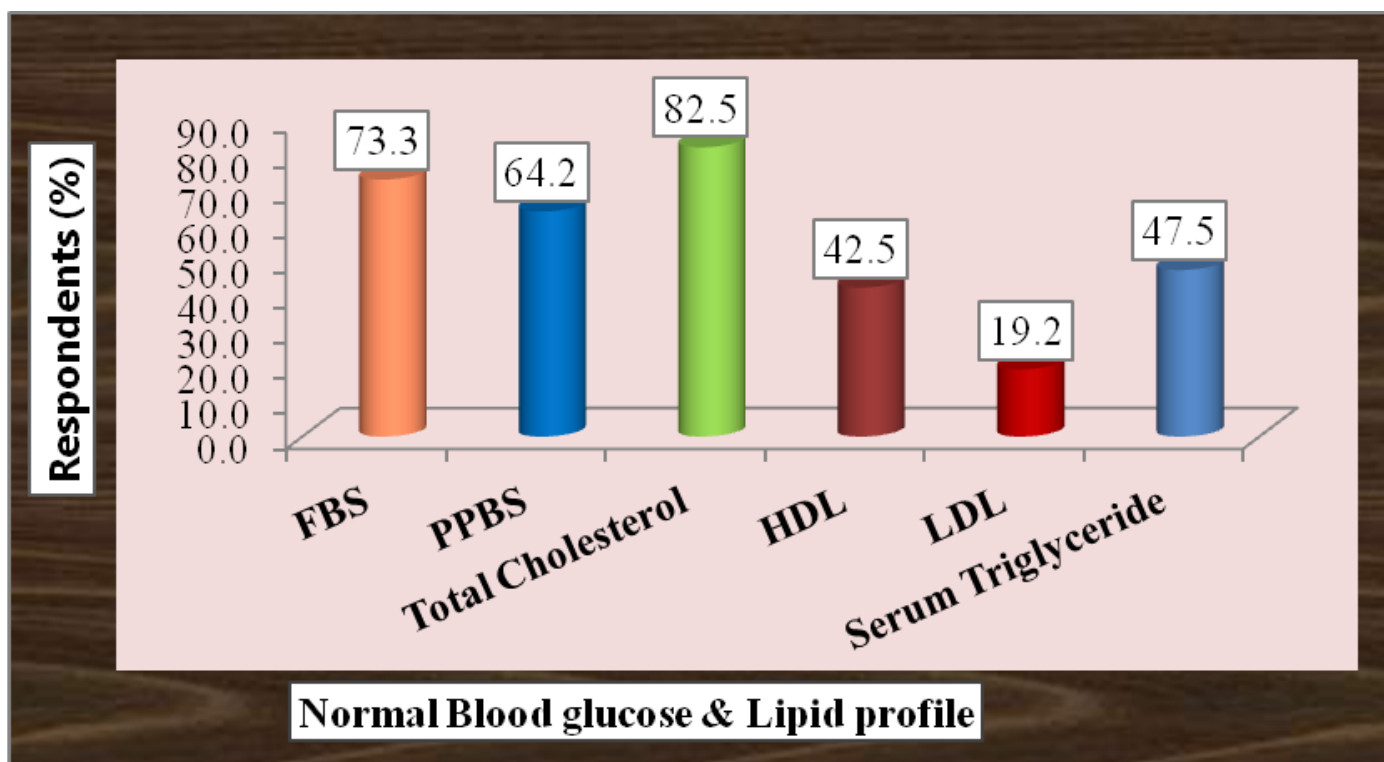

Figure 4: Response on Blood glucose\& Lipid profile values 
Rashmi $R$ et.al. Nutritional status and physical activity pattern as risk factors for non-communicable diseases among occupational bus drivers.

Fig 4 states the Blood glucose parameters and lipid profile of the subjects.

TABLE - 7. Mean consumption of Nutrients in comparison with Recommended Dietary Allowance (RDA), N=120

\begin{tabular}{|c|c|c|c|c|c|c|}
\hline \multirow{2}{*}{ No. } & \multirow{2}{*}{ Nutrients } & \multirow{2}{*}{ RDA } & \multicolumn{2}{|c|}{ Consumption } & \multirow{2}{*}{ Adequacy (\%) } & \multirow{2}{*}{$\begin{array}{l}\text { 't' } \\
\text { Test }\end{array}$} \\
\hline & & & Mean & SD & & \\
\hline 1 & Energy (Kcal) & 2320 & 1631 & 228 & 77.3 & $25.30 * *$ \\
\hline 2 & Protein (g) & 42.9 & 53.3 & 9.0 & 124.2 & $12.66 * *$ \\
\hline 3 & Fat (g) & 25 & 35.2 & 9.2 & 140.8 & $12.15^{* *}$ \\
\hline
\end{tabular}

Table 7 gives the Mean consumption of Nutrients in comparison with Recommended Dietary Allowance (RDA), it showed significant difference at 5\% level of significance.

TABLE - 8. Mean consumption of Nutrients in comparison with Estimated Average Requirement (EAR), N=120

\begin{tabular}{|l|l|l|l|l|l|l|}
\hline \multirow{2}{*}{ No. } & \multirow{2}{*}{ Nutrients } & \multirow{2}{*}{ EAR } & \multicolumn{2}{|c|}{ Consumption } & Adequacy (\%) & 't' \\
\cline { 4 - 5 } & & & Mean & SD & & Test \\
\hline 1 & Energy (Kcal) & 2110 & 1631 & 228 & 77.3 & $23.01^{* *}$ \\
\hline 2 & Protein (g) & 60 & 53.3 & 9.0 & 123.9 & $8.15^{* *}$ \\
\hline 3 & Fat (g) & 25 & 35.2 & 9.2 & 140.8 & $12.15^{* *}$ \\
\hline \multicolumn{6}{|c}{$t(0.05,119 d f)=2.58$}
\end{tabular}

Table 8 gives the Mean consumption of Nutrients in comparison with estimated average requirement (EAR), it showed significant difference at $5 \%$ level of significance.

TABLE - 9. Correlation coefficient between Nutrients and Lipid profile and Blood glucose parameters, $N=120$

\begin{tabular}{|l|l|l|l|l|}
\hline \multirow{2}{*}{ No. } & \multirow{2}{*}{ Parameters } & \multicolumn{3}{|c|}{ Correlation (r) with Nutrients } \\
\cline { 3 - 5 } & & Energy & Protein & Fat \\
\hline I & Blood Profile & & & \\
\hline 1 & FBS & +0.034 & +0.065 & +0.028 \\
\hline 2 & PPBS & +0.048 & +0.064 & +0.086 \\
\hline II & Lipid Profile & & & \\
\hline 1 & Total Cholesterol & +0.068 & +0.106 & +0.042 \\
\hline 2 & LDL & -0.004 & +0.023 & +0.046 \\
\hline 3 & HDL & +0.017 & -0.081 & -0.053 \\
\hline 4 & Serum Triglyceride & +0.135 & +0.108 & -0.167 \\
\hline
\end{tabular}

Table 9 depicts the correlation between intake of energy, protein and fat with blood glucose level and lipid profile.

TABLE - 10. Correlation coefficient between Sleeping duration and Body mass index with Lipid profile and Blood glucose parameters, $\mathrm{N}=120$

\begin{tabular}{|l|l|l|l|}
\hline \multirow{2}{*}{ No. } & \multirow{2}{*}{ Parameters } & \multicolumn{2}{|l|}{ Correlation (r) with } \\
\cline { 3 - 4 } & & Sleep duration & Body mass index \\
\hline I & Blood Profile & & \\
\hline 1 & FBS & -0.055 & -0.142 \\
\hline 2 & PPBS & -0.041 & -0.047 \\
\hline II & Lipid Profile & & \\
\hline 1 & Total Cholesterol & -0.084 & +0.126 \\
\hline 2 & LDL & -0.061 & +0.129 \\
\hline 3 & HDL & +0.068 & -0.201 \\
\hline 4 & Serum Triglyceride & -0.023 & +0.128 \\
\hline
\end{tabular}

Table 10 shows the correlation of lipid profile with sleep duration and BMI of the subjects.

TABLE - 11. Association between Age group with Lipid profile and Blood glucose parameters, $\mathrm{N}=120$

\begin{tabular}{|c|c|c|c|c|c|c|c|c|}
\hline \multirow{3}{*}{ No. } & \multirow{3}{*}{ Parameters } & \multicolumn{6}{|c|}{ Association with Age group (years) } & \multirow{3}{*}{$\begin{array}{l}\chi^{2} \\
\text { Test }\end{array}$} \\
\hline & & \multicolumn{2}{|c|}{$30-39(n=24)$} & \multicolumn{2}{|c|}{$40-49(n=54)$} & \multicolumn{2}{|c|}{$50-59(n=42)$} & \\
\hline & & $\mathbf{N}$ & $\%$ & $\mathbf{N}$ & $\%$ & $\mathbf{N}$ & $\%$ & \\
\hline I & Blood Profile & & & & & & & \\
\hline 1 & FBS & 23 & 95.8 & 39 & 72.2 & 26 & 61.9 & $9.05 *$ \\
\hline 2 & PPBS & 22 & 91.7 & 33 & 61.1 & 22 & 52.4 & $10.65^{*}$ \\
\hline II & Lipid Profile & & & & & & & \\
\hline 1 & Total Cholesterol & 20 & 83.3 & 43 & 79.6 & 36 & 85.7 & $0.62^{\mathrm{NS}}$ \\
\hline 2 & LDL & 6 & 25.0 & 8 & 14.8 & 9 & 21.4 & $1.33^{\mathrm{NS}}$ \\
\hline 3 & HDL & 10 & 41.7 & 23 & 42.6 & 18 & 42.9 & $0.01^{\mathrm{NS}}$ \\
\hline 4 & Serum Triglyceride & 11 & 45.8 & 27 & 50.0 & 21 & 50.0 & $0.13^{\mathrm{NS}}$ \\
\hline
\end{tabular}


Rashmi $R$ et.al. Nutritional status and physical activity pattern as risk factors for non-communicable diseases among occupational bus drivers.

Table 11 shows that there was a significant difference among different age group in Blood glucose parameters, whereas no significant difference for the same in lipid profile at $5 \%$ level of significance.

TABLE - 12. Response on Frequency consumption of Foods, $N=120$

\begin{tabular}{|c|c|c|c|c|c|c|c|c|}
\hline \multirow[t]{2}{*}{ No. } & \multirow[t]{2}{*}{ Food groups } & \multicolumn{7}{|c|}{ Respondents (\%) } \\
\hline & & Never & Daily & Weekly twice & Weekly once & Fort nightly & Monthly & Occasionally \\
\hline I & Cereals & & & & & & & \\
\hline 1 & Rice & 0.0 & 95.8 & 4.2 & 0.0 & 0.0 & 0.0 & 0.0 \\
\hline 2 & Wheat & 5.0 & 17.5 & 44.2 & 23.3 & 9.2 & 0.8 & 0.0 \\
\hline 3 & Ragi & 8.3 & 55.0 & 17.5 & 9.2 & 5.8 & 3.3 & 0.8 \\
\hline 4 & Jowar & 49.2 & 27.5 & 5.8 & 9.2 & 4.2 & 2.5 & 1.7 \\
\hline 5 & Navane & 88.3 & 1.7 & 1.7 & 2.5 & 3.3 & 2.5 & 0.0 \\
\hline 6 & Arka & 95.8 & 0.8 & 1.7 & 0.0 & 0.0 & 0.8 & 0.8 \\
\hline 7 & Baragu & 94.2 & 0.8 & 1.7 & 0.0 & 0.8 & 1.7 & 0.8 \\
\hline 8 & Saame & 95.0 & 0.8 & 1.7 & 0.0 & 0.0 & 1.7 & 0.8 \\
\hline 9 & Sajje & 90.8 & 1.7 & 3.3 & 0.0 & 0.8 & 0.8 & 2.5 \\
\hline II & Pulses & & & & & & & \\
\hline 1 & Turdal & 0.0 & 84.2 & 10.0 & 5.0 & 0.8 & 0.0 & 0.0 \\
\hline 2 & Moong dal & 0.8 & 25.8 & 21.7 & 38.3 & 10.0 & 3.3 & 0.0 \\
\hline 3 & BengalGram dal & 1.7 & 13.3 & 27.5 & 35.8 & 10.8 & 8.3 & 2.5 \\
\hline 4 & Soya & 85.0 & 2.5 & 0.0 & 4.2 & 0.8 & 4.2 & 3.3 \\
\hline 5 & Urad dal & 1.7 & 27.5 & 35.0 & 30.0 & 5.0 & 0.8 & 0.0 \\
\hline III & Milk \& Products & & & & & & & \\
\hline 1 & Milk & 9.2 & 82.5 & 4.2 & 1.7 & 1.7 & 0.0 & 0.8 \\
\hline 2 & M.Products & 0.0 & 70.0 & 20.8 & 4.2 & 4.2 & 0.0 & 0.8 \\
\hline 3 & Ghee & 21.7 & 12.5 & 16.7 & 20.8 & 15.0 & 5.0 & 8.3 \\
\hline 4 & Butter & 68.3 & 2.5 & 3.3 & 10.8 & 2.5 & 5.8 & 6.7 \\
\hline 5 & Dalda & 93.3 & 0.8 & 0.8 & 0.8 & 0.0 & 0.8 & 3.3 \\
\hline IV & Vegetable & & & & & & & \\
\hline 1 & Roots\& Tubers & 0.0 & 34.2 & 30.8 & 27.5 & 3.3 & 2.5 & 1.7 \\
\hline 2 & Green leafy veg. & 0.0 & 40.0 & 44.2 & 15.0 & 0.8 & 0.0 & 0.0 \\
\hline 3 & Other Veg & 0.0 & 55.0 & 27.5 & 14.2 & 2.5 & 0.8 & 0.0 \\
\hline $\mathrm{V}$ & Fruits & & & & & & & \\
\hline 1 & Fruits & 2.5 & 20.0 & 25.8 & 29.2 & 17.5 & 4.2 & 0.8 \\
\hline 2 & Nuts & 7.5 & 8.3 & 7.5 & 18.3 & 13.3 & 14.2 & 30.8 \\
\hline VI & Beverages & & & & & & & \\
\hline 1 & Alcoholic & 61.7 & 3.3 & 6.7 & 13.3 & 5.0 & 5.0 & 5.0 \\
\hline 2 & Non Alcoholic & 0.8 & 22.5 & 33.3 & 25.8 & 12.5 & 2.5 & 2.5 \\
\hline VII & Others & & & & & & & \\
\hline 1 & Bakery & 23.3 & 7.5 & 14.2 & 26.7 & 15.0 & 6.7 & 6.7 \\
\hline 2 & Fast foods & 30.0 & 3.3 & 6.7 & 20.0 & 19.2 & 7.5 & 13.3 \\
\hline 3 & Fried foods & 15.0 & 6.7 & 19.2 & 26.7 & 22.5 & 6.7 & 3.3 \\
\hline 4 & Sweets & 14.2 & 7.5 & 11.7 & 26.7 & 16.7 & 11.7 & 11.7 \\
\hline
\end{tabular}

Table 12 depicts the frequency of consumption of different food group among the subjects.

\section{DISCUSSION}

The present study was conducted in a tertiary care hospital in Bangalore. 120 subjects included were employees of Karnataka State Road Transport Corporation (KSRTC). The main aim of the study was to assess the nutritional status of the subject with respect to anthropometry, physical activity, sleep and dietary pattern of the subjects. The data obtained was correlated with Lipid profile and blood glucose level to study the risk of Non Communicable Diseases.
The mean age of the subjects was found to be 44 years with majority of them (45\%) in the age group of 40-49 years. Similar results were shown in a study done by Sr. Kanikkai Parvin. et al. where $61 \%$ of the subjects were in the age group of 40-50 years [10]. Present study reported that 43.3\% had completed Secondary School Leaving Certificate (SSLC) exam and majority were driver cum conductor by profession (Table 1). This will create a lot of occupational stress on the subjects. A study done by Takilkar C S revealed that $57.8 \%$ exhibits moderate level of stress score and significantly associated with hypertension [11]. It was reported that $73.3 \%$ of the subjects had mixed diet pattern 
in the present study among which $37.5 \%$ consumed non veg weekly(Table 2).However in a study a higher percentage of the study population (99.4\%) reported mixed diet pattern, among which 55.8\% consumed non veg on most of the days in a week reports Arjun Lakshman et al.[12].20\% skip their meals everyday whereas $40 \%$ skip it sometimes due to work pressure and time constraints, majority (39.2\%) usually skip the lunch because of long travelling period and lack of break time(Table 3). On contrary as per Sasikala devi S, 61.4\% skip their breakfast and only $15.3 \%$ skip their lunch [13]. Interestingly present study reports that $59.2 \%, 55.8 \%$ and $39.2 \%$ of the subjects eat breakfast, lunch and dinner from outside source every day respectively (Fig 1). Supporting this Arjun Lakshman et al. states that $62.6 \%$ eat their meals from restaurants [13]. This could be one of the cardiovascular risk factors among the subjects.

Anthropometric data reports that majority (36.7\%) of the subject's height falls in the range of 166 to $170 \mathrm{~cm}$ and $42.5 \%$ of the subject's weight ranges between $71-80 \mathrm{Kg}$. BMI of the subjects categorizes $50.8 \%$ to be Pre-obese with BMI of 25 to $29.9 \mathrm{Kg} / \mathrm{m}^{2}$ (Table 4, Fig 2). Similar result was reported by Sr. Kanikkai Parvin et al. with $49 \%$ of the study population to have BMI range of 25 to $29.9 \mathrm{Kg} / \mathrm{m}^{2}[10]$. A study done by Chankaramangalam Mathew Anil reported $50 \%$ of the subject's BMI to be $>25 \mathrm{Kg} / \mathrm{m}^{2}$ [14]. Conversely Saimak Pourabdin.et al. reports $39.1 \%$ of the study population to have BMI ranging between $25-29.9 \mathrm{Kg} / \mathrm{m}^{2}$ [15], which is lower compared to the present study. Besides previous study also reports significant association of Age with BMI [15] whereas present study reports no significant difference in BMI among different age group; 30-39 years, 40-49 years, 50-59 years respectively (Table 5).

Assessing Physical activity pattern revealed that majority (74.2\%) were not indulged in any kind of physical activity, although Sr. Kanikkai et al. reports only
$11 \%$ of the subjects were doing physical activity [10]. Sleep duration reported that $56.7 \%$ of the subjects sleep for 6-7 hours yet subjects self-reported that the sleep was disturbed; it was either in the break time or day time combined with fatigue (Fig 3). Alexander M Crizzle et al. states that sleep apnea in association with stress and underlying medical condition can increase the crash risk [16].Co morbidity status revealed that an overall of $46.7 \%$ of the subjects had Hypertension, Diabetes, etc. among which $17.5 \%$ were diabetic (Table 6), whereas Lakshman et al. reports $13 \%$ of the subjects to be diabetic in his study [12], which is lesser than the present study.

Present study proclaims that $8.35 \%$ of the subjects were smokers, $21.7 \%$ were alcoholics and $21.7 \%$ were tobacco chewers (Table 6). On contrary, Lakshman et al. reports $46 \%, 86.3 \%$ and $15.6 \%$ of the study population to be Smokers, alcoholic and tobacco chewers respectively [12], which is way too higher than the present study. A 38year follow-up study of UK men showed that baseline differences in tobacco use, High blood pressure and cholesterol were associated with a 10- to 15-year shorter life expectancy [17]. Increased smoking indicates elevated number of tobacco related deaths in developing countries [18]. By the year 2030, WHO (2008) projects that over $80 \%$ of tobacco-related deaths are to occur in young people in developing countries [19].

Furthermore, biochemical parameters reports $17.5 \%, 80.8 \%$ and $52.5 \%$ of the subjects to have elevated total cholesterol, Low Density Lipoprotein and Serum Triglycerides respectively. Also $57.5 \%$ shows lower High Density Lipoprotein. A study done by Farzanch Monlazerifar et al. reveals that $76.7 \%$ had higher Triglycerides and $81.4 \%$ had lower High Density Lipoprotein [20]. H Nasri M D et al. Reports $67 \%$ of study population $(n=194)$ had elevated Low Density Lipoprotein and was significantly associated with Coronary Artery Disease $\left(\mathrm{p}=0.0001^{*}\right)$ at 5\% level of significance [21]. 
On comparing with Recommended Dietary Allowance (RDA) 2010, adequacy of calories, protein and fat is reported to be $77 \%, 124.2 \%$ and $140.8 \%$ respectively. Similar results were reported when compared with Estimated Average Requirement (EAR) 2020 (Table 7, 8). On performing ' $t$ ' test, a significant difference was seen between intake and RDA 2010 and EAR 2020 for energy, protein and fat. Majority of the subjects derive their protein from animal source, excessive protein intake do have adverse effect on the health of an individual which results in irregularities of bone and calcium homeostasis. Lower fluid intake accompanied with increased protein consumption increases the renal acid excretion and acid load which in turn results in hypercalciuria and calcium kidney stones. Excessive protein intake increases the risk of cancer and cardiovascular diseases [22].

It was observed that fat intake is almost 1.5 times higher than the requirement, which could be detrimental. The intake of saturated fats and Trans fats in the form of deep fried foods, bakery foods, meat, junk etc (Table 12) is encountered. Also majority (73.3\%) used sunflower oil for cooking at home. A study done by Sowmya Narasimhan et al. reported that excessive fat intake was significantly associated with risk of abdominal obesity, hypertension and fasting blood glucose, which indeed are the components of metabolic syndrome. Adding to this previous study also states that using sunflower oil for cooking had significant association with above mentioned components $(p<0.001)$ [23]. Sunflower oil due to its higher emission of aldehydes, independent of cooking method is carcinogenic reports Chiung-Yu Peng et al. [24].

Present study reveals a weak positive correlation of total cholesterol, LDL and Serum Triglyceride with BMI whereas a negative correlation with HDL (Table 10). Supporting this Magna Manjareeka et al. also reports a weaker correlation of lipid profile with BMI, but shows a comparatively stronger correlation with waist circumference [25].

\section{CONCLUSION}

The present study gives an overview of nutritional status of the subjects which is alarming and increases their risk for noncommunicable diseases. Adding to this is physical inactivity, sleep apnea and tobacco use resulting in abdominal obesity; a precursor of non-communicable diseases. Effective repeated counseling and educating on healthy eating; short duration physical activity in leisure time will improve lifestyle and reduce the risk of many noncommunicable diseases such as cardiovascular diseases, diabetes, hypertension, and cancer.

\section{ACKNOWLEDGEMENT}

We would like to express our heartfelt gratitude and thank Dr. C N Manjunath sir, Director, Sri Jayadeva Institute of Cardiovascular Sciences and Research for his support, guidance and permitting us to conduct this study in the institute.

We are grateful to Prof. $\mathrm{H} \mathrm{S}$ Surrendra, Statistician, Department of Statistics, University of Agricultural Sciences, GKVK, Bangalore for helping in statistical analysis.

We would express our heartfelt gratitude to Dr. Navaneetha.R, Assistant professor, Department of Food and Nutrition, Smt.V H D Central Institute of Home science, Bangalore for peer reviewing the research article and giving her valuable inputs.
Abbreviations
RDA: Recommended Dietary Allowances.
EAR: Estimated Average Intake.
BMI: Body Mass Intake.
FBS: Fasting Blood Sugar
PPBS: Post Prandial Blood Sugar
CVD: Cardio Vascular Diseases
HDL: High Density Lipoproteins
LDL: Low Density Lipoproteins 
GOD-POD: Glucose Oxidase-Peroxidase. CHOD-PAP: Cholesterol Oxidase Phenol 4-Aminoantipyrine Peroxidase.

GPO-PAP: Glycerine Phosphate Oxidase Peroxidase.

\section{Acknowledgement: None}

\section{Conflict of Interest: None}

\section{Source of Funding: None}

\section{Ethical Approval: Approved}

\section{REFERENCES}

1. Thiese MS, Moffitt G, Hanowski RJ, Kales SN, Porter RJ, Hegmann KT. Commercial Driver Medical Examinations: Prevalence of Obesity, Co morbidities, and Certification Outcomes. JOccupEnvironMed.2015; 57(6): 659-655.

2. Robinson, C.F. and Burnett, C.A.Truck drivers and heart disease in the United States.Am.J.Ind.Med. 1979-1990.47.

3. Lee NS, Lee KJ, Kim JJ, Lee JW. The Relationship between Job Stress and Dyslipidemia in Express Bus Drivers. Korean J Occup Environ Med. 2010; 22(3):221-229.

4. Bhatt B, Seema MS. Occupational Health Hazards: A Study of Bus Drivers. Journal of Health Management. 2012; 14(2):201-206.

5. Frances R Jack, Maria G Piacentini, Monika J.A Schröder, Perception and Role of Fruit in the Workday Diets of Scottish Lorry Drivers. Appetite, Volume 30, Issue 2, 1998, Pages 139-149.

6. McDonough, B., Howard, M., Angeles, R. et al. Lone workers attitudes towards their health: views of Ontario truck drivers and their managers. BMC. 2014. Res Notes (7), 297.

7. Nagler, E.M., Viswanath, K., Ebbeling, C.B. et al. Correlates of fruit and vegetable consumption among construction laborers and motor freight workers. Cancer Causes Control. 2013. (24), 637-647.

8. Laura Cristina Tibiletti Balieiro, LuanaThomazettoRossato, Jim Waterhouse, Samantha Lemos Paim, Maria Carliana Mota \& Cibel Aparecida Crispim. Nutritional status and eating habits of bus drivers during the day and night, ChronobiologyInternational.2014.112 3-1129.

9. Hemiö K, Puttonen S, Viitasalo K, et al. Food and nutrient intake among workers with different shift systems. Occupational and Environmental Medicine. 2015. (72): 513-520.

10. Sr. Kanikkaiparvin, Devakirubai, Nalini Jeyavanth Santha, G. Selvarani. Assessment of Risk Status of Coronary artery disease in Terms of selected risk factors among bus drivers. Asian J. Nursing Education and Research. 2020; 10(3): 291-297.

11. Takilkar CS. Occupational stress and its associated health disorders among bus drivers. Int $\mathrm{J}$ Community Med Public Health. 2016 Jan;3(1):208-211

12. ArjunLakshman, NeerajManikath, Asma Rahim, V. P. Anilakumari. Prevalence and Risk Factors of Hypertension among Male Occupational Bus Drivers in North Kerala, South India: A Cross-Sectional Study. ISRN Preventive Medicine Volume. 2014, Article ID 318532, 9 pages.

13. Sasikaladevi, S. A Morbidity study of Health Related Risk Factors of Bus Drivers of Metropolitan Transport Corporation Limited. Annals of R.S.C.B Chennai 2014.Pages. 1266 - 1276.

14. Chankaramangalam MathewAnil, Ramamo orthy Veyilmuthu, Muthuraja Dhanush, Saravanan Prem Anand Ethayakumari, Rajan V Xavier Christu. International Journal of Medical Research \& Health Sciences. Sciences. 2017, Volume : 6, Issue : 5

15. SiamakPourabdian, ParastooGolshiri, Mohs en Janghorbani. Overweight, underweight, and obesity among male long-distance professional drivers in Iran. Journal of occupational health. 2020.

16. AlexanderM.Crizzle ${ }^{\mathrm{a}}$ PhilipBigelow ${ }^{\text {bc }}$ Diane Adams $^{\mathrm{a} S}$ SpencerGooderham ${ }^{\mathrm{b}}$ Anita,M.Myers ${ }^{\mathrm{b}}$

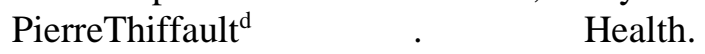
Volume, December 2017, Pages 90-109.

17. Clarke R, Emberson J, Fletcher A, Breeze E, Marmot M, Shipley $M$ J et al.Life Expectancy in relation to cardiovascular risk factor: 38year follow-up of 19000 men in the Whitehall study. BMJ 2009; 339:b3513.

18. Shafey, O.Eriksen. M., Ross. H., \&Macky. J. The tobacco atlas. American Cancer Society.2009. 
Rashmi $R$ et.al. Nutritional status and physical activity pattern as risk factors for non-communicable diseases among occupational bus drivers.

19. WHO Report On The Global Tobacco Epidemic, 2008: The Mpower Package. World Health Organization, Geneva. 2008

20. Montazerifar F, Karajibani M , Pirmoradi B, Torki Z, Moradpour M, et al. Prevalence of Metabolic Syndrome in Professional Drivers, Zahedan J Res Med Sci. 2019 ; 21(3):e79768.

21. H NasriMD (1), M Moazenzadeh MD (2). Coronary Artery Disease risk factors in drivers versus people in other occupations. Arya Journal, 2006, 2(2): 75-78.

22. IoannisDelimaris. Adverse Effects Associated with Protein Intake above the Recommended Dietary Allowance for Adults. Hindawi Publishing Corporation ISRN Nutrition Volume 2013, Article ID 126929, pg: 6.

23. SowmyaNarasimhan, LakshmipriyaNagaraj an, RuchiVaidya, GeethaGunasekaran, Gaya thriRajagopal, VijayalakshmiParthasarathy, RanjitUnnikrishnan, Ranjit Mohan Anjana, Viswanathan Mohan, and Vasudevan Sudha. Dietary fat intake and its association with risk of selected components of the metabolic syndrome among rural South Indians. Indian J
EndocrinolMetab. 2016 Jan-Feb; 20(1): 4754.

24. Chiung-Yu Peng Dr. P.H.Effects of cooking method, cooking oil, and food type on aldehyde emissions in cooking oil fumes. Materials Volume, 15 February 2017, Pages 160-167.

25. Manjareeka M, Nanda S, Mishra J, Mishra S. Correlation between anthropometry and lipid profile in healthy subjects of Eastern India. J Midlife Health. 2015; 6(4):164-168.

26. Ms. Meenakshi Bajaj. Diet Metrics. $1^{\text {st }}$ edition. Chennai: Notion Press; 2019.

27. $\mathrm{T}$ Longvah. $\mathrm{R}$ Ananthram. $\mathrm{K}$ Bhaskarachary. K Venkaiah. Indian Food Composition Table (IFCT). $1^{\text {st }}$ edition. Hyderabad: National Institute of Nutrition. Indian Council of Medical Research; 2017.

How to cite this article: Rashmi R, Vidyavati $\mathrm{H}$ G, C N Manjunath. Nutritional status and physical activity pattern as risk factors for noncommunicable diseases among occupational bus drivers. Int J Health Sci Res. 2021; 11(12):103113. DOI: https://doi.org/10.52403/ijhsr. 20211216 